\title{
The Role of Economic Uncertainty in Forecasting Exchange Rate Returns and Realized Volatility: Evidence from Quantile Predictive Regressions
}

\author{
Christina Christou ${ }^{*}$, Rangan Gupta $^{* *}$, Christis Hassapis ${ }^{* * *}$ and Tahir Suleman ${ }^{* * * *}$
}

\begin{abstract}
In this paper, we investigate whether the news-based measure of economic policy uncertainty (EPU), can be used to forecast exchange rate returns and volatility using a quantile regression approach, which accounts for persistence and endogeneity, using data from thirteen different countries. Our main findings suggest that: (i) EPU is useful for forecasting exchange rate returns and volatility, (ii) forecasting ability-quantile order relationships exhibit U-shape, possibly asymmetric form around the median and (iii) asymmetries are more pronounced in the case of forecasting volatility.
\end{abstract}

Keywords: Economic Policy Uncertainty; Exchange Rate Returns; Volatility; Quantile Predictive Regressions; Developed and Emerging Markets

JEL classification: C32; C53; E60; F31

\footnotetext{
${ }^{*}$ Corresponding author. School of Economics and Management, Open University of Cyprus, 2252, Latsia, Cyprus. Email: christina.christou@ouc.ac.cy.

** Department of Economics, University of Pretoria, Pretoria, 0002, South Africa. Email: rangan.gupta@ up.ac.za.

*** School of Economics and Management, Department of Economics, University of Cyprus, P.O. Box 20537, CY1678 Nicosia, Cyprus. Email: kristis@ucy.ac.cy.

***** School of Economics and Finance, Victoria University of Wellington, New Zealand and School of Business, Wellington Institute of Technology, New Zealand. Email: tahir.suleman@ @uw.ac.nz.
} 


\section{Introduction}

The foreign exchange market is the largest and most liquid financial market in the world. As reported in the Triennial Survey of global foreign exchange market volumes, of the Bank for International Settlement (BIS), the average daily turnover was 5.1 trillion U.S. dollars in April of 2016. In light of the importance of currency markets, accurate forecasting of exchange rate returns and volatility is of paramount importance to various economic agents. Forecasting of exchange rate is of interest, to not only investors but also exporters and importers - retailers and consumers, who ultimately take decisions based on the value of the domestic currency and its volatility. Moreover, policymakers are concerned with pass-through, a major mechanism by which the exchange movements affect domestic economic aggregates. In this regard, the literature on predictability of exchange rate returns and volatility is voluminous, to say the least. Detailed literature reviews are provided by Rapach and Wohar (2002, 2004, 2006), Bacchetta and van Wincoop (2013), Rossi (2013), Plakandaras et al., (2013, 2015a,b 2017), Pilbeam and Langeland (2015), Huber (2016, 2017), Papadimitriou et al., (2016), Bryne et al., (2016, forthcoming). One common observation that emerges out of this literature is that, despite the great need, the task of forecasting exchange rate movements based on fundamentals, is an arduous task.

In a recent study, Balcilar et al., (2016) provide evidence of in-sample predictability of returns and volatility, of sixteen U.S. dollar-based exchange rates (for both developed and developing countries), emanating from the differential between domestic and US and the economic policy uncertainty (EPU), using a quantiles-based framework. The EPU indices used, in turn, are based on data from an internet search and count of articles that use keywords associated with economic policy uncertainty in these countries. Balcilar et al., (2016) notes that if domestic uncertainty is 
higher (lower) than uncertainty in the foreign economy at a given point in time, then domestic agents would prefer to invest into assets denominated in the foreign (domestic) currency, resulting in an impact on the movements of the exchange rate (i.e., in its returns and volatility). In addition to this direct channel, given that returns of financial assets are functions of the state of the economy, which in turn are subject to fluctuations caused by uncertainty, this suggests, an indirect channel through which uncertainty can affect exchange rate returns and volatility, as indicated by Martin and Urrea (2007) and Benigno et al., (2012), based on new Keynesian general equilibrium frameworks.

Besides Balcilar et al., (2016), the relationship between uncertainty on exchange rate returns and volatility is limited to only few studies. Benigno et al., (2012) uses vector autoregressive (VAR) and panel VAR models to analyze the impact of domestic uncertainties (modelled through conditional volatilities of monetary policy, inflation-target and productivity shocks) on the dollar-based real exchange rates of the G6 countries. Colombo (2013) uses a VAR model to analyze the impact of U.S. uncertainty on the nominal euro-dollar exchange rate and Sin (2015) uses the same approach to study the effect of shocks to Chinese uncertainty on the real exchange rates of Taiwan and Hong Kong relative to the Chinese Yuan. In general, these studies find a significant impact on exchange rates following uncertainty shocks. Krol (2014), is the only study that analyses the contemporaneous effect of domestic and US uncertainties separately, on the volatility of ten dollar-based nominal exchange rates of industrialized and developing countries, based on linear regressions. The author finds that, for the more integrated industrial economies, there is strong evidence that both home country and U.S. economic policy uncertainty increases currency volatility during recessions, while, for the less integrated emerging economies, only 
home country economic policy uncertainty increases exchange rate volatility, during recessionary episodes. ${ }^{1}$

As can be seen from the above discussion, all the studies dealing with uncertainty and exchange rate movements are in-sample based analysis. Given the widespread consensus, in the empirical literature, that in-sample predictability does not guarantee out-of-sample forecasting gains, with predictive models requiring out-of-sample validation (Campbell, 2008), the objective of this paper, is to conduct an elaborate forecasting exercise for returns and (realized) volatility, for 13 exchange rates (Australia, Brazil, Canada, Chile, China, EU, India, Japan, Korea, South Africa, Russia, Singapore, and UK), based on information content of news-based EPU differentials. For our purpose, we rely not only on standard linear predictive regressions, but also on the quantilesbased model of Lee (2016), that controls for endogeneity and persistence of the predictor, characteristics we statistically show to exist for the EPU differentials.

The decision to rely on quantile regressions in this paper is motivated by the in-sample predictability study of Balcilar et al., (2016) discussed above. As shown by Bryne et al., (2016, forthcoming), and in particular by Balcilar et al., (2016), the relationship between exchange rate movements and its predictors, in this case EPU differentials, is not linear. Given this, the literature has resorted to Markov-switching, smooth transition threshold, neural networks, non or semi-parametric and time-varying coefficient models (see for example, Rapach and Wohar (2006), Bacchetta and van Wincoop (2013), Rossi (2013), Plakandaras et al., (2015a), Bryne et al., (2016, forthcoming), Huber (2016, 2017), and Papadimitriou et al., (2016) for detailed

\footnotetext{
${ }^{1}$ In terms of the literature on uncertainty and exchange rates, Ismailov and Rossi (2017) provide a new exchange rate uncertainty index, which measures how unpredictable exchange rates are relative to their historical past. Then, these authors use the new measure of uncertainty to provide empirical evidence that uncovered interest rate parity does hold in five industrialized countries relative to the US dollar, at times when uncertainty is not exceptionally high and breaks down during periods of high uncertainty.
} 
literature reviews). In this paper, we address the issue of non-linearity (and non-normality), by considering the quantile regression framework. The quantile-based approach is clearly more informative relative to any linear model, as it investigates the ability of the EPU differentials to forecast the entire conditional distribution of exchange rate returns and volatility, rather than being restricted just to the conditional-mean. Looking at just the conditional mean of the currency returns and volatility series, this may 'hide 'interesting characteristics as it can lead us to conclude that a predictor has poor predictive performance, while it is actually valuable for predicting the lower or/and the upper quantiles of returns. Note that, on one hand, unlike the Markov-switching and the smooth threshold models, we do not need to specify number of regimes of the excess returns (for instance bear and bull) in an ad hoc fashion with the quantile model. On the other hand, the quantile approach has added advantage over the non- or semiparametric, neural networks and time-varying approaches, as we can study each point of the conditional distribution characterizing the existing state of the currency market.

In addition, business cycle fluctuations are likely to induce the slope coefficients associated with the predictor, to vary across quantiles to the extent that EPU differential may contain significant information for some parts of the return and volatility distributions only. The quantile predictive regression approach, which allows us to integrate this information, would thus lead to additional benefits over the standard linear and popular nonlinear methods. Note that, since the quantile regression approach studies the entire conditional distribution, which captures various states of the currency market, it has an inherent time-varying nature to the estimation process. Though, by pursuing a recursive estimation of both the conditional-mean and quantile predictive regression models over the out-of-sample period (which is based on a 50 percent spilt of the full 
sample (as in Rapach et al., 2005)), we make both the models to have time-varying parameters in the forecast evaluation part of the sample.

To the best of our knowledge, this is the first attempt to analyse the forecastability of the EPU differentials returns and volatility of exchange rates, for 13 major developed and developing economies, utilizing a quantile regression approach that controls for endogeneity and persistence of predictors. The rest of the paper is organized as follows: section 2 presents the econometric methodology, while section 3 describes the data and discusses the results. Section 4 concludes.

\section{Methodology}

In this section, we describe the predictive regression models, as well as the estimation methods considered in this study.

\subsection{Predictive Quantile Regression Methodology}

Let us first consider a standard predictive mean regression of the form

$\Upsilon_{t+k}=\beta_{0}+\beta_{1} x_{t}+u_{t+k}$

with $E\left(u_{t+k} / I_{t}\right)=0$, where $X_{t}$ is a single predictor, and $I_{t}$ the natural filtration, and $Y_{t+k}$ is the cumulative returns or volatility over the period $t$ to $t+k$. The above specification is probably the most appropriate model for predicting the conditional mean. However, mean regressions may fail to correctly predict $Y$, especially when nonlinearities and outliers are present. In this study, we adopt the quantile regression (QR) approach initially developed by Koenker and Basset (1978). 
The QR methodology enable us to investigate the whole conditional distribution, since it analyses the response of the dependent variable vis-à-vis the explanatory variable at each quantile. Furthermore, QR estimators are more robust, than mean regression estimators, to the presence of nonlinearities and outliers, which is of great importance in our forecasting environment.

\subsubsection{Conventional $Q R$ approach}

A predictive $\mathrm{QR}$ may be specified as:

$Y_{t+k}=\beta_{0, \tau}+\beta_{1, \tau} x_{t}+u_{t+k}$,

with $E\left(u_{t+k} / I_{t}\right)=0$, where $X_{t}$ is a single predictor, and $I_{t}=\sigma\{u, j \leq t\}$ the natural filtration. The conditional quantile of $Y_{t+k}$ such that $P\left(Y_{t+k} \leq Q_{Y_{t+k}}\left(\tau / I_{t}\right) / I_{t}\right)=\tau \in(0,1)$ is

$Q_{Y_{t+k}}\left(\tau / I_{t}\right)=\beta_{0, \tau}+\beta_{1, \tau} x_{t}$

Model (2) analyzes quantile predictability as well as the median of $Y_{t+k}$. This feature is well suited to the analysis of financial asset returns. Estimators of the parameters $\beta_{0, \tau}$ and $\beta_{1, \tau}$, can obtained as the solution to

$\min _{\beta_{0}, \beta_{1}} T^{-1} \sum_{t=1}^{T} \rho_{\tau}\left(Y_{t+k}-\beta_{0, \tau}-\beta_{1, \tau} \chi_{t}\right)$,

where $\rho_{\tau}(u)=u(\tau-1(u<0))$, the asymmetric loss function, usually referred to as the check function, and $1(\cdot)$ the indicator function. Then, the forecast of the $\tau$ th quanile of the distribution of the dependent variable $Y$ is obtained as $\hat{Y}_{t+k, \tau}=\hat{\beta}_{0, \tau}+\hat{\beta}_{1, \tau} X_{t}$.

However, Lee (2016) argues that conventional QR econometric techniques are not valid when regressors are highly persistent. Lee (2016) developed quantile econometric methods for robust 
inference in the presence of persistent and endogenous regressors. Specifically, Lee (2016) develops a new QR methodology (called IVX-QR) which corrects size distortions arising from regressors' persistence by adopting the IVX filtering method proposed by Magdalinos and Phillips (2009).

\subsubsection{The IVX-QR approach}

Lee (2016) developed quantile econometric methods for inference and prediction allowing for persistent and endogenous regressors. It is known that conventional quantile regression methods are invalid when predictors are highly persistent. In our case, EPU is highly persistent. Consider the simple predictive model in mean (Eq. 1) with the predictor $\mathcal{X}_{t}$ following an autoregressive form:

$x_{t}=R_{n} x_{t-1}+\varepsilon_{t}$

where, $R_{n}=1+\frac{C}{n^{\alpha}}$, for some $\alpha>0$, and $\mathrm{n}$ is the sample size. The specification in Eq.5 is designed to handle predictor variables with various degrees of persistence since it captures four categories of regressor's persistence: stationary, mildly integrated, local to unity and unit root, and mildly explosive.

Now, consider a linear QR model given in equations (2) and (3), with the natural filtration $I_{t}=$ $\sigma\left\{U_{j}=\left(u_{j}, \varepsilon_{j}\right), j \leq t\right\}$

Lee (2016) suggests that it is convenient to transform model (2) to remove the intercept term:

$Y_{t+k, \tau}=\beta_{1, \tau} X_{t}+u_{t+k, \tau}$ 
where $Y_{t+k, \tau}:=Y_{t+k}-\hat{\beta}_{0, \tau}^{Q R}(\tau)=\Upsilon_{t+k}-\beta_{0, \tau}+O_{p}\left(n^{-1 / 2}\right)$ is the zero-intercept QR dependent variable. This is analogous to the demeaning process in a predictive mean regression. Further, Lee (2016) adopts the IVX filtering of Magdalinos and Phillips (2009). The main idea of IVX filtering is to filter $x_{t}$ to generate $\tilde{Z}_{t}$ with mild persistence - intermediate between first differencing and the use of levels data. In particular,

$\tilde{z}_{t}=R_{n z} \tilde{z}_{t-1}+\Delta X_{t}, \quad R_{n z}=1+\frac{c_{z}}{n^{\delta}}$

where $\delta \in(0,1), c_{z}<0, \tilde{z}_{0}=0$. The parameters $\delta \in(0,1)$ and $c_{z}<0$ are specified by the researcher.

Lee (2016) proposed new IVX-QR estimation methods that are based on the use of IVX filtered instruments. The IVX-QR estimator $\hat{\beta}_{1, \tau}$ for $\beta_{1, \tau}$ is defined as

$\hat{\beta}_{1, \tau}^{I V X Q R}=\arg \underbrace{\inf }_{\beta_{1}}\left(\sum_{t=1}^{n} m_{t}\left(\beta_{1}\right)\right)^{\prime}\left(\sum_{t=1}^{n} m_{t}\left(\beta_{1}\right)\right)$,

where $m_{t}\left(\beta_{1}\right)=\tilde{z}_{t-1}\left(\tau-1\left(\gamma_{t, \tau} \leq \beta_{1} x_{t}\right)\right)$.

Considering that the null hypothesis of interest in predictive regression is of the form $H_{0}: \beta_{1, \tau}=$ 0, Lee (2016) proposed a computationally attractive testing procedure. Based on the fact that $\tilde{Z}_{t}$ and $\mathcal{X}_{t}$ are "close" to each other, the author uses ordinary QR regressions on $\tilde{z}_{t}$ to test $H_{0}$ : $\beta_{1, \tau}=0$.

Specifically, first we consider an ordinary QR regression of $\Upsilon_{t, \tau}$ on $\tilde{z}_{t}$ and estimate the slope coefficient: 
$\hat{\gamma}_{1, \tau}^{I V X Q R}=\arg \underbrace{\min }_{\gamma_{1}}\left(\sum_{t=1}^{n} \rho_{t}\left(\gamma_{t, \tau}-\gamma_{1}^{\prime} \tilde{z}_{t}\right)\right)$.

Then, it can be shown that under $H_{0}: \beta_{1, \tau}=0$,

$\widehat{f_{u_{o t}}(0)}(\tau(1-\tau))^{-1}\left(\hat{\gamma}_{1, \tau}^{I V X Q R}-\beta_{1, \tau}\right)^{\prime}\left(\tilde{Z}^{\prime} \tilde{Z}\right)\left(\hat{\gamma}_{1, \tau}^{I V X Q R}-\beta_{1, \tau}\right) \rightarrow \chi^{2}(1)$,

where $\tilde{Z}^{\prime} \tilde{Z}=\sum_{t=2}^{n} \tilde{z}_{t} \tilde{z}_{t}^{\prime}$.

\subsection{Forecast accuracy}

To evaluate the out-of-sample forecasting ability of our models, this study focuses on the relative mean square forecast error:

$R M S F E_{i}=\frac{M S F E_{i}}{M S F E_{b, i}}$

where $M S F E_{i}=\sum_{t=P+1}^{T}\left(\Upsilon_{t}-\widehat{Y}_{i, t}\right)^{2}$ is the mean square forecast error of the i model, $M S F E_{b, i}$ is the mean square error of the benchmark forecasting model, and $\mathrm{P}$ is the in-sample period size. Values of $R M S F E_{i}$ less than 1, indicate superior forecasting ability of model $i$ relative to the benchmark model.

To statistically assess whether the performance of model i outperforms the benchmark model, we employ the McCracken's (2007) MSE-F test. The MSE-F statistic is formally defined as

$M S E_{i}-F=(T-1-R)\left[\frac{M S E_{b, i}}{M S E_{i}}-1\right]$

where $R$ is the number of observations in the first in-sample portion. The $M S E-F$ statistic is a one-sided test for equal forecast accuracy. More specifically, MSE-F is formulated under the null that the forecast error from the alternative model $\left(M S E_{i}\right)$ is equal to or larger than the forecast 
error from the benchmark $\left(M S E_{b, i}\right)$. A rejection of the null indicates that the alternative model has superior forecast performance than the benchmark.

To conduct the exercise, we split the total sample of $T$ observations into an in-sample period of the first $\mathrm{P}$ observations and an out-of-sample of the consequent $T$ - $P$ observations. The predictive regression models are estimated recursively, by adding one observation to the estimation sample at each step, with $R$ set equal to $T / 2$.

We now turn our attention to the main focus of the paper, i.e., the out-of-sample forecasting of returns and volatility of exchange rates. We consider the following two models: Model 1: $R_{t}=$ $\alpha_{1}+\beta_{1} E P U_{t-1}+u_{t}$, and; Model 2: $V_{t}=\alpha_{2}+\beta_{2} E P U_{t-1}+u_{t}$, where $R_{t}$ is the exchange rates returns, $\quad V_{t}$ is the exchange rates volatility, and $E P U_{t}$ the economic policy uncertainty index differential between the domestic economy and the US. The natural benchmark forecasting model is the historical mean model, according to which the forecast coincides with the estimate of $\alpha_{i}, i=1,2$. Since the focus of the paper is to explore the forecasting ability of our models at all point of the conditional distributions of forecasting of returns and volatility of exchange rates, we consider the quantile regression versions of Models 1 and 2:

$R_{t}=\alpha_{1, \tau}+\beta_{1, \tau} E P U_{t-1}+u_{t}$,

and

$V_{t}=\alpha_{2, \tau}+\beta_{2, \tau} E P U_{t-1}+u_{t}$

with the benchmark model being a quantile regression with only a constant. 


\section{Data and Results}

\subsection{Data}

Our analysis is based on thirteen U.S. dollar based exchange rates, namely, Australia, Brazil, Canada, Chile, China, EU, India, Japan, Korea, South Africa, Russia, Singapore, UK$^{2}$ and the differential of the U.S. EPU from the respective domestic EPUs. Barring the case of South Africa, for which the EPU is only available at a quarterly frequency, monthly data is used for the remaining twelve exchange rates. Table A1 in the Appendix, notes the sample period of each of the currencies used in our analysis, with the start and end date being purely driven by data availability. The data on the U.S. dollar exchange rates for these countries are obtained from the Datastream database, maintained by Thomson Reuters. Exchange rate returns are defined as the first-differences of the natural logarithmic values of the exchange rates. Following Plakandaras et al., (2017), realized volatility is computed from the sum of daily squared returns over a month or quarter. As shown in the summary statistics of Table A1, the exchange rate returns and volatilities are non-normal and hence, provide an initial motivation to use quantile regressions.

Since uncertainty is unobservable, obtaining an appropriate measure for it is not straightforward. For this, three main approaches have been used: (a) The News-based approach of and Brogaard and Detzel (2015), and Baker et al., (2016), whereby the authors perform month-by-month searches of newspapers for terms related to economic and policy uncertainty in order to construct their measure of economic policy uncertainty; (b) The method of Mumtaz and Zanetti (2013), Jurado et al., (2015), Mumtaz and Theodoridis (2017, forthcoming), and Carriero et al., (2017) involves recovering measures of uncertainty from stochastic volatility in the error structure of

\footnotetext{
${ }^{2}$ For the UK, besides the sample reported in Table A1, we have also use a second dataset that spans the period from January 1900 to December 2008. Results obtained from the second dataset are qualitatively similar to those reported in the paper, and are available upon request from the authors.
} 
estimated structural VAR models, and; (c) Finally, the approach by Rossi and Sekhposyan (2015, 2017), and Scotti (2016), where these authors have developed measures of uncertainty based on the dispersion of forecasts of key macroeconomic variables produced by the professional forecasters. While there exists no clear-cut consensus in terms of which approach to use in constructing measures of uncertainty, the news-based measures of uncertainty, as developed by Baker et al., (2016), seems to have gained tremendous popularity in various applications in macroeconomics and finance. This is most likely due to the fact that data needed for this approach are easily available not only for the US, but for other European and emerging economies as well. More importantly, the use of this method does not require any complicated estimation of a model to generate it in the first place. The data is available for download for all countries barring South Africa from: www.policyuncertainty.com. For South Africa, the data is obtained from the news-based approach of Hlatshwayo and Saxegaard (2016), who follows the framework of Baker et al., (2016), and is available for download from: https://sites.google.com/site/sandile1984hlatshwayo/miscellaneous-stuff. Since the exchange rate is a relative price, in our paper, we work with differentials between the natural logarithmic values of the EPU, of a specific country or region and the natural logarithmic values of the EPU of the U.S.

Before we move into the forecasting exercise of the model, it is important to test for the persistence and endogeneity of the EPU differentials, to motivate the IVX-QR methodology instead of the standard quantile regressions. As it can be seen from Table A2, in the Appendix, there is overwhelming evidence in favor of non-stationarity in the EPU differentials. In addition, following the test of endogeneity, suggested by Narayan and Gupta (2015), we can see that evidence in favor of endogeneity is in general weak, with endogeneity showing up for Australia, 
Brazil, Chile and India under returns, and China for realized volatility. However, endogeneity of EPUs relative to the exchange rates have been stressed in Colombo (2013) and Sin (2015), and in particular by Duca and Saving (2017), and thus, we cannot completely ignore the issue of EPU differentials being endogenous regressors.

\subsection{Empirical analysis}

Table 1, reports the forecast evaluation of exchange rates returns and volatility at the conditional mean. In particular, it presents the RRMSE of models 1 and 2 relative to the historical average benchmark. Note that values of RRMSE lower than 1, indicate a superior forecasting performance of the predictive model relative to the historical average benchmark. Our results suggest that model 1 has RRMSE lower than one and statistically significant, in the case of China for $\mathrm{h}=1$, in the case of Korea for $\mathrm{h}=12$, and in Australia, Chile and the UK for $\mathrm{h}=24$. In the case of forecasting exchange rate volatility (model 2), our forecasting model beats the historical average in six economies (Australia, Brazil, Chile, China, Eu, India) for $\mathrm{h}=1$, in five economies (Brazil, Canada, Chile, EU, India) for $\mathrm{h}=12$, and 4 economies (Brazil, Canada, China, EU) for $\mathrm{h}=24$.

We now examine the forecasting ability of model 1 at different quantiles of the exchange rates returns distribution. For this purpose, we employ the IVX-QR approach developed by Lee (2016). In general, our results, presented in Table 2, suggest that model 1 outperforms the historical average benchmark for all countries and all considered forecasting horizons. The only exception is South Africa; in this case model 1 fails to beat the benchmark for $\mathrm{h}=1,12$. 
Our results for forecasting horizon $\mathrm{h}=1$ (Table 2, Panel A), reveal that for most countries, the forecasting ability-quantile relationship exhibits, a possibly asymmetric, U-shaped form around the median of the exchange rate returns distribution, with the degree of asymmetry being country dependent. More specifically, it is immediately apparent that model 1 outperforms the historical average benchmark at low and high order quantiles, suggesting a U-shaped relationship between forecasting ability and quantiles' order. For example, in the case of the EU, the forecasting ability-quantile relationship can be characterized as U-shaped and relatively symmetric; model 1 outperforms the benchmark at all quantiles except the median. In the case of the UK, the relationship between quantiles' order and forecasting ability, is also U-shaped but asymmetric; while model 1 beats the benchmark, at all lower than the median quantiles, at higher than the median quantiles, it outperforms the benchmark only at quantiles 0.80, 0.90 and 0.95 . In general, for forecasting horizon $\mathrm{h}=1$, all countries exhibit $\mathrm{U}$-shaped forecasting ability-quantile relationship. The only exceptions are China and South Africa. In the case of China, model 1 outperforms the average historical benchmark only at low quantiles $(0.05,0.10,0.20)$, while in the case of South Africa, model 1 fails to beat the benchmark at all quantiles.

For forecasting horizon $\mathrm{h}=12$, the results reported in Panel $\mathrm{B}$ of Table 2, are qualitatively the same as the results for $h=1$. In the case of $h=24$ (Table 2, Panel $C$ ), the results show that all countries, except South Africa, exhibit U-shaped forecasting ability-quantile relationships.

Let us now consider the forecasting ability of model 2 at different quantiles of the conditional distribution of exchange rates volatility. Table 3 reports the results. The association between forecasting ability and quantiles' order for $\mathrm{h}=1$ (Panel A) can be well described as asymmetric U-shaped for 8 countries (Australia, Brazil, India, Japan, Korea, Russia, Singapore and the UK). For 3 countries (Canada, Chile and South Africa) model 2 outperforms the 
benchmark, only at low order quantiles. Contrary, in the case of the EU, model 2 beats the benchmark only at the right tail quantile of 0.95 . Lastly, in the case of China, model 2 fails to outperform the historical average benchmark only at quantiles greater than 0.70 .

For forecasting horizon $\mathrm{h}=12$ (Table 3, Panel B), 6 countries (Australia, Brazil, India, Japan, Korea and Russia) continue to exhibit asymmetric U-shaped forecasting ability-quantile relationship. For Canada, Chile, South Africa and Singapore, model 2 demonstrates superior forecasting ability only at low order quantiles. For the EU and the UK, our model beats the benchmark only at quantile 0.95 , while for the case of China, model 2 fails to outperform the historical average benchmark only at quantiles greater than 0.80 .

For forecasting horizon $\mathrm{h}=24$ (Table 3, Panel C), our results are very similar to those reported for $\mathrm{h}=1$ and $\mathrm{h}=12$. Specifically, 7 countries (Australia, Brazil, Canada, Chile, Japan, Korea and Russia) continue to exhibit asymmetric U-shaped forecasting ability-quantile relationship. For India, South Africa and Singapore, model 2 demonstrates superior forecasting ability, only at low order quantiles. For the EU, our model beats the benchmark, only at quantile 0.95 , while for the case of China, model 2 fails to outperform the historical average benchmark only at quantiles greater than 0.80 . Lastly, in the case of the UK our model fails to beat the benchmark at all quantiles.

To assess the sensitivity of our findings, to the quantile regression methodology employed, we repeat the exercise using conventional quantile regressions as described in section 2.1.1. Results for model 1 and model 2 are reported in Tables A3 and A4 in the Appendix. It is immediately apparent from Tables A3 and A4, that most of the empirical regularities observed in Tables 2 and 3 (Tables 2 and 3 report results derived under IVX-QR method) are no longer present; for 
most countries we no longer observe the U-shaped forecasting ability-quantiles relationships. Under conventional QR estimation, forecasting results are strongly heterogeneous across countries. However, we need to stress out that results derived under conventional QR estimation methods, might be not valid due to the endogeneity and non-stationarity of the EPU differentials (see Table A1).

More specifically, our results, presented in Table A3, suggest that for forecasting horizon $\mathrm{h}=1$, model 1, fails to outperform the historical average benchmark at all quantiles, in four countries (Japan, Korea, South Africa and Russia). In the case of Brazil, Canada and Singapore, model 1 beats the benchmark at specific low order quantiles, while in a group of countries (Australia, Chile, China, India and the UK) it outperforms the benchmark at specific high order quantiles. In the case of the EU, we observe that model 1 beats the benchmark, at low order quantiles up to 0.30 and at quantile 0.80 . Results for model 1 and forecasting horizons $\mathrm{h}=12,24$ (Panels B and C of Table A3) are qualitatively similar.

Results for forecasting ability of model 2 and forecasting horizon $\mathrm{h}=1$, are presented in Panel A of Table A4. For Australia, Brazil, Korea, Singapore and the UK, model 2 fails to demonstrate superior forecasting ability at high order quantiles. The opposite holds for the case of China and the EU. For Chile and Russia, our model beats the benchmark at quantiles around the median. In the case of South Africa, model 2 fails to outperform the historical average benchmark at all quantiles, while for Canada model 2 beats the benchmark only at quantile 0.05. Lastly, Japan is the only country for which we observe a U-shaped forecasting ability-quantile relationship. Results for model 2 and forecasting horizons $\mathrm{h}=12,24$ (Panels B and C of Table A4) are qualitatively similar.

\section{Conclusions}


This paper investigates exchange rates returns and volatility quantile predictability, using the news-based measure of economic policy uncertainty (EPU) as predictor. Specifically, we use the IVX-QR method of Lee (2016) to examine the forecasting ability of EPU, at various quantiles of the exchange rates returns and volatility distributions, in ten economies (Australia, Brazil, Canada, Chile, China, European Union, India, Japan, Korea, South Africa, Russia, Singapore, United Kingdom).

The quantile regression framework reveals a U-shaped, possibly asymmetric around the median, relationship between forecasting ability and quantiles' order. More specifically, in the case of forecasting exchange rates returns using EPU as predictor, our results suggest a pronounced Ushaped forecasting ability-quantiles order association; EPU demonstrates superior forecasting ability, at low and high order quantiles, in all countries except South Africa. In the case of forecasting exchange rates volatility, the forecasting ability-quantiles order relationship also exhibits the characteristic U-shape. However, the observed U-shaped patterns are more asymmetric but less pronounced. For example, while forecasting volatility one period ahead, we observe U-shaped relationships between forecasting ability and quantiles order, in eight countries. 


\section{References}

Bacchetta, P., and Van Wincoop, E. (2013). On the unstable relationship between exchange rates and macroeconomic fundamentals. Journal of International Economics, 91, 18-26.

Baker, S. R., Bloom, N., \& Davis, S. J. (2016). Measuring economic policy uncertainty. The Quarterly Journal of Economics, 131(4), 1593-1636.

Balcilar, M., Gupta, R., Kyei, C. and Wohar, M.E., (2016). Does economic policy uncertainty predict exchange rate returns and volatility? Evidence from a nonparametric causality-inquantiles test. Open Economies Review,27(2), 229-250.

Benigno, G., Benigno, P. and Nisticò, S. (2012). Risk, monetary policy, and the exchange rate. NBER Macroeconomics Annual, 26(1), 247-309.

Brogaard, J. and Detzel, A. (2015). The asset-pricing implications of government economic policy uncertainty. Management Science, 61, 3-18.

Byrne, J., Korobilis, D. and Ribeiro, P. (2016). Exchange Rate Predictability in a Changing World. Journal of International Money and Finance, 62, 1-24.

Byrne, J., Korobilis, D. and Ribeiro, P. (Forthcoming). On the Sources of Uncertainty in Exchange Rate Predictability. International Economic Review.

Campbell, J.Y., (2008). Viewpoint: estimating the equity premium, Canadian Journal of Economics, 41, 1-21.

Carriero, A., Clark, T., and Marcellino, M. (forthcoming). Measuring uncertainty and its impact on the economy, The Review of Economics and Statistics.

Colombo, V. (2013). Economic policy uncertainty in the US: Does it matter for the Euro area? Economics Letters, 121(1), 39-42.

Duca, J.V., and Saving, J.L. (2017). What Drives Economic Policy Uncertainty in the Long and Short Runs? European and U.S. Evidence over Several Decades. Journal of Macroeconomics, https://doi.org/10.1016/j.jmacro.2017.09.002. 
Hlatshwayo, S., and Saxegaard, M. (2016). The Consequences of Policy Uncertainty: Disconnects and Dilutions in the South African Real Effective Exchange Rate-Export Relationship. IMF Working Paper No. WP/16/113.

Huber, F. (2016). Forecasting Exchange Rates using Multivariate Threshold Models, B.E. Journal of Macroeconomics, 16(1), 193-201.

Huber, F. (2017). Structural breaks in Taylor rule based exchange rate models - Evidence from threshold time varying parameter models, Economics Letters, 150, 48-52.

Ismailov, A., and Rossi, B. (2017). Uncertainty and deviations from uncovered interest rate parity. Journal of International Money and Finance, DOI: https://doi.org/10.1016/j.jimonfin.2017.07.012.

Jurado, K., Ludvigson, S. C., \& Ng, S. (2015). Measuring Uncertainty. The American Economic Review, 105(3), 1177-1216.

Koenker, R. and Bassett Jr, G. (1978). Regression quantiles. Econometrica: journal of the Econometric Society, 33-50.

Krol, R. (2014). Economic policy uncertainty and exchange rate volatility. International Finance, 17(2), 241-256.

Lee, J.H. (2016). Predictive quantile regression with persistent covariates: IVX-QR approach, Journal of Econometrics 192, 105-118.

Magdalinos, T., Phillips, P.C.B. (2009). Econometric inference in the vicinity of unity. CoFie Working Paper (7), Singapore Management University.

Martin, J.A.J., and Urrea, R.P. (2007). The Effects Of Macroeconomic And Policy Uncertainty On Exchange Rate Risk Premium. International Business and Economics Research Journal, 6(3), $29-48$.

McCracken, M.W. (2007). Asymptotics for out-of-sample tests of Granger causality, Journal of Econometrics, 140, 719-752. 
Mumtaz, H. and Theodoridis, K. (2017). Common and country specific economic uncertainty. Journal of International Economics, 105, 205-216.

Mumtaz, H., and Theodoridis, K. (forthcoming). The changing transmission of uncertainty shocks in the US: An empirical analysis. Journal of Business and Economic Statistics. http://dx.doi.org/10.1080/07350015.2016.1147357.

Mumtaz, H., and Zanetti, F. (2013). The impact of the volatility of monetary policy shocks. Journal of Money, Credit and Banking, 45, 535-558.

Narayan, P.K., Gupta, R. (2015). Has oil price predicted stock returns for over a century? Energy Economics 48, 18-23.

Papadimitriou, T., Gogas, P., and Plakandaras, V. (2016). Testing Exchange Rate models in a Small Open Economy: an SVR approach. Bulletin of Applied Economics, 3(2), 6-29.

Plakandaras, V., Papadimitriou, T., and Gogas, P. (2013). Directional forecasting in financial time series using support vector machines: the USD/ Euro exchange rate. Journal of Computational Optimization in Economics and Finance, 5(2) 125-138.

Plakandaras, V., Papadimitriou, T., and Gogas, P. (2015a). Forecasting monthly and daily exchange rates with machine learning methodologies. Journal of Forecasting, 34(7), 560-573.

Plakandaras, V., Papadimitriou, T., and Gogas, P. and Konstantinos, D. (2015b). Market Sentiment and Exchange Rate Directional Forecasting. Algorithmic Finance, 4(1-2), 69-79.

Plakandaras, V., Gupta, R., and Wohar M.E. (2017). The depreciation of the pound post-Brexit: Could it have been predicted? Finance Research Letters, 21, 206-213.

Pilbeam, K. and Langeland, K.N., 2015. Forecasting exchange rate volatility: GARCH models versus implied volatility forecasts. International Economics and Economic Policy, 12(1), pp.127142.

Rapach, D.E., and Wohar, M. E. (2002). The Monetary Model of Exchange Rate Determination: New Evidence from a Century of Data. Journal of International Economics, 58(2), 359-385. 
Rapach, D.E., and Wohar, M. E. (2004). Testing the Monetary Model of Exchange Rate Determination: A Closer Look at Panels. Journal of International Money and Finance, 23(6), $841-865$.

Rapach, D.E., Wohar, M.E., and Rangvid, J. (2005). Macro Variables and International Stock Return Predictability. International Journal of Forecasting, 21(1), 137-166.

Rapach, D. E., and Wohar, M. E. (2006). The out-of-sample forecasting performance of nonlinear models of real exchange rate behavior. International Journal of Forecasting, 22(2), 341-361.

Rossi, B. (2013). Exchange rate predictability. Journal of economic literature, 51(4), 1063-1119.

Rossi, B. and Sekhposyan, T. (2015). Macroeconomic uncertainty indices based on nowcast and forecast error distributions. The American Economic Review, 105(5), pp.650-655.

Rossi, B., and Sekhopsyan, T. (2017). Macroeconomic Uncertainty Indices for the Euro Area and its Individual Member Countries, Empirical Economics 53(1), 41-62.

Scotti, C. (2016). Surprise and uncertainty indexes: Real-time aggregation of real-activity macro surprises. Journal of Monetary Economics, 82, 1-19.

Sin, C.Y.C. (2015). The economic fundamental and economic policy uncertainty of Mainland China and their impacts on Taiwan and Hong Kong. International Review of Economics \& Finance, 40, 298-311. 
Table 1: Forecast evaluation results for exchange rates returns and volatility at the conditional mean.

\begin{tabular}{|c|c|c|c|c|c|c|}
\hline \multirow[t]{2}{*}{ Countries } & \multicolumn{3}{|c|}{ Exchange rate returns } & \multicolumn{3}{|c|}{ Exchange rate volatility } \\
\hline & $h=1$ & $\mathrm{~h}=12$ & $\mathrm{~h}=24$ & $\mathrm{~h}=1$ & $\mathrm{~h}=12$ & $\mathrm{~h}=24$ \\
\hline Australia & 1.0123 & 0.9929 & $0.9835^{*}$ & $0.9537 * * *$ & 1.0094 & 1.0006 \\
\hline Brazil & 1.0056 & 1.0127 & 1.0154 & $0.9078 * * *$ & $0.9390 * * *$ & $0.9294 * * *$ \\
\hline Canada & 0.9943 & 1.0009 & 0.9923 & 1.0275 & $0.9733 * *$ & $0.9794 * *$ \\
\hline Chile & 1.0024 & 1.0170 & $0.9833^{* *}$ & $0.9598 * * *$ & $0.9362 * * *$ & 1.0309 \\
\hline China & $0.9798 * *$ & 1.0062 & 1.0056 & $0.8809 * * *$ & 0.9965 & $0.9703 * *$ \\
\hline India & 1.0074 & 1.0019 & 1.0085 & $0.7998 * * *$ & $0.9582 * *$ & 1.0311 \\
\hline Japan & 1.0367 & 1.0011 & 0.9933 & 1.0165 & 0.9985 & 0.9956 \\
\hline Korea & 1.0069 & $0.9885^{*}$ & 1.0386 & 0.9957 & 0.9969 & 1.0911 \\
\hline South Africa & 1.0282 & 1.0882 & 1.0013 & 1.0573 & 1.2789 & 1.0354 \\
\hline Russia & 1.0138 & 1.0180 & 1.1209 & 1.1376 & 1.0541 & 1.8338 \\
\hline UK & 1.0186 & 1.0096 & $0.9861 *$ & 1.0020 & 1.0166 & 1.0109 \\
\hline
\end{tabular}

Notes: All figures are relative RMSFE (R-RMSFE), i.e., ratios of MSFEs to the MSFE of the historical average benchmark

model. A R-RMSFE below unity indicates that the forecasting model over-performs the benchmark forecasting model according to the MSFE metric. * **, ** denote rejection of the null of equal MSEs according to the McCracken (2007) MSE-F statistic at $10 \%, 5 \%$, and $1 \%$ level of significance, respectively. h-step-ahead forecasts are generated recursively. 
Table 2: Forecasting exchange rate returns: Forecast evaluation results relative to the historical average benchmark model at various horizons under IVX-QR estimation

Countries

0.05

$$
0.10
$$

0.20

0.30

0.40

Quantiles

Panel $\mathrm{A}$ : $\mathrm{h}=1$ period ahead

Brazil

$$
0.5472^{* * *}
$$

$0.6423^{* * *} \quad 0.8193^{* * *}$

$0.9502 * *$

$0.9830 * *$

$0.5403^{* * *}$

$0.6602^{* * *}$

$0.8486^{* * *}$

$0.9380^{* * *}$

$0.9654^{* * *}$

$0.7385^{* * *}$

$0.84477^{* * *}$

Canada

Chile

China

$0.4418^{* * *}$

$0.5566^{* * *}$

$0.6493 * *$

$0.7501^{* * *}$

$0.8730 * * *$

$0.9653^{* * *}$

$0.9439 * * *$

$0.9932 *$

$0.9863^{* *}$

$0.9397^{* * *}$

$0.3356 * *$

$0.6660 * * *$

$0.8523^{* * *}$

$0.8054^{* * *}$

$0.9460^{* * *}$

$0.6575^{* * *}$

$0.7252^{* * *}$

$0.8555^{* * *}$

$0.9290 * * *$

$0.8992 * * *$

0.9985

$0.9815^{* *}$

$0.4784^{* * *}$

$0.6404^{* * *}$

$0.7347^{* * *}$

$0.9195^{* * *}$

1.1024

South Africa

1.5365

1.4199

1.1639

$0.6497^{* * *} \quad 0.7680^{* * *}$

$0.8889^{* *}$

1.1141

$0.9585^{* * *}$

1.0000

Singapore

$0.4063^{* * *}$

$0.3723^{* * *}$

$0.6207^{* * *}$

$0.8017^{* * *}$

$0.9366^{* * *}$

$0.7680^{* * *} \quad 0.9335^{* * *}$

$0.4487^{* * *}$

$0.5828^{* * *}$

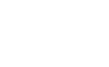

\begin{tabular}{|c|c|c|c|c|c|c|c|c|c|c|c|}
\hline Australia & $0.6533^{* * *}$ & $0.7199 * * *$ & $0.8767^{* * *}$ & $0.97377^{* *}$ & 0.9994 & $0.9717^{* *}$ & $0.9262^{* * *}$ & $0.8264 * * *$ & $0.7610^{* * *}$ & $0.5928^{* * *}$ & $0.5459 * * *$ \\
\hline Brazil & $0.4350^{* * *}$ & $0.5213^{* * *}$ & $0.7283^{* * *}$ & $0.8582^{* * *}$ & $0.9381^{* * *}$ & 1.0184 & 1.0506 & 1.05060 & 1.0969 & $0.8849 * * *$ & $0.6782^{* * *}$ \\
\hline
\end{tabular}

Panel B: $\mathrm{h}=12$ periods ahead ( 4 periods for SA) 


\begin{tabular}{|c|c|c|c|c|c|c|c|c|c|c|c|}
\hline Canada & $0.4132 * * *$ & $0.5347^{* * *}$ & $0.7213^{* * *}$ & $0.8262^{* * *}$ & $0.9407^{* * *}$ & 1.0001 & 1.0281 & 1.0104 & $0.9514 * * *$ & $0.8055^{* * *}$ & $0.6270^{* * *}$ \\
\hline Chile & $0.7494 * * *$ & $0.8323^{* * *}$ & $0.9552^{* * *}$ & 1.0063 & 1.0355 & 1.0365 & $0.9879 *$ & $0.9169 * * *$ & $0.7653^{* * *}$ & $0.6724 * * *$ & $0.5793 * * *$ \\
\hline China & $0.6931^{* * *}$ & $0.8204^{* * *}$ & $0.9711^{* * *}$ & 0.9939 & 1.00030 & 1.0021 & 1.0005 & 0.9995 & 0.9974 & 1.0140 & 1.0004 \\
\hline EU & $0.3365 * * *$ & $0.4701 * * *$ & $0.6642 * * *$ & $0.8298 * * *$ & $0.9626 * * *$ & 1.0203 & $0.9700 * * *$ & $0.8586 * * *$ & $0.6607 * * *$ & $0.4501 * * *$ & $0.3627^{* * *}$ \\
\hline India & $0.4458 * * *$ & $0.5959 * * *$ & $0.8039 * * *$ & $0.8457^{* * *}$ & $0.9470 * * *$ & 0.9949 & 1.0188 & 1.0286 & $0.9331^{* * *}$ & $0.6388^{* * *}$ & $0.3656 * * *$ \\
\hline Japan & $0.3772 * * *$ & $0.4858^{* * *}$ & $0.6499 * * *$ & $0.8346^{* * *}$ & $0.9668^{* * *}$ & $0.9808^{* *}$ & $0.8925^{* * *}$ & $0.7496^{* * *}$ & $0.6360 * * *$ & $0.4777 * * *$ & $0.3822^{* * *}$ \\
\hline Korea & $0.4815^{* * *}$ & $0.6523 * * *$ & $0.8079 * * *$ & $0.9012 * * *$ & $0.9804^{* *}$ & 0.9952 & $0.9806 * *$ & $0.9450 * * *$ & $0.8091^{* * *}$ & $0.5177^{* * *}$ & $0.3086 * * *$ \\
\hline South Africa & 1.4871 & 1.3323 & 1.1689 & 1.0057 & 1.0222 & 1.0266 & 1.0394 & 1.0650 & 1.0791 & 1.1151 & 1.2396 \\
\hline Russia & $0.6636^{* * *}$ & $0.7742^{* * *}$ & $0.8827^{* * *}$ & $0.9440 * * *$ & 0.9963 & 1.0200 & 1.0420 & 1.0743 & 1.1447 & 1.1166 & $0.8482 * * *$ \\
\hline Singapore & $0.3588^{* * *}$ & $0.4723 * * *$ & $0.5989 * * *$ & $0.7963^{* * *}$ & $0.9374 * * *$ & 1.0036 & 1.0070 & $0.9714^{* *}$ & $0.8657^{* * *}$ & $0.5507^{* * *}$ & $0.3618^{* * *}$ \\
\hline UK & $0.4323^{* * *}$ & $0.5060 * * *$ & $0.6191 * * *$ & $0.7923 * * *$ & $0.9358^{* * *}$ & 0.9945 & 1.0059 & $0.9350 * * *$ & $0.8168^{* * *}$ & $0.6889 * * *$ & $0.5012^{* * *}$ \\
\hline
\end{tabular}

Panel $\mathrm{C}: \mathrm{h}=24$ periods ahead ( 8 periods for SA)

\begin{tabular}{|c|c|c|c|c|c|c|c|c|c|c|c|}
\hline Australia & $0.7245^{* * *}$ & $0.7857^{* * *}$ & 0.9982 & 1.1002 & 1.0956 & $0.9898^{*}$ & $0.9034 * * *$ & $0.8076^{* * *}$ & $0.7237^{* * *}$ & $0.6173^{* * *}$ & $0.5461 * * *$ \\
\hline Brazil & $0.5313^{* * *}$ & $0.5993 * * *$ & $0.8066 * * *$ & $0.9092 * * *$ & $0.9382 * * *$ & 0.9919 & $0.9854^{*}$ & $0.9273^{* * *}$ & $0.8405^{* * *}$ & $0.6351 * * *$ & $0.4690 * * *$ \\
\hline Canada & $0.4286^{* * *}$ & $0.5645^{* * *}$ & $0.7454 * * *$ & $0.8458 * * *$ & $0.9507 * * *$ & $0.9865^{*}$ & 0.9945 & $0.9341^{* * *}$ & $0.8393 * * *$ & $0.6778 * * *$ & $0.5240 * * *$ \\
\hline Chile & $0.8446 * * *$ & $0.9637^{* * *}$ & 1.0068 & 1.0826 & 1.0813 & 1.0244 & $0.9521 * * *$ & $0.8959 * * *$ & $0.7622^{* * *}$ & $0.6626 * * *$ & $0.5793 * * *$ \\
\hline China & $0.7275^{* * *}$ & 1.0219 & 1.0729 & 1.0180 & 1.0092 & 1.0043 & 1.0009 & 0.9984 & 0.9940 & $0.9845^{*}$ & $0.9626^{* * *}$ \\
\hline EU & $0.3697^{* * *}$ & $0.5056^{* * *}$ & $0.6967^{* * *}$ & $0.8506 * * *$ & $0.9558^{* * *}$ & 0.9956 & $0.9413 * * *$ & $0.8161^{* * *}$ & $0.5971^{* * *}$ & $0.3963^{* * *}$ & $0.3079 * * *$ \\
\hline India & $0.4803^{* * *}$ & $0.6888^{* * *}$ & $0.8357^{* * *}$ & $0.8572^{* * *}$ & $0.9560^{* *}$ & 1.0011 & 1.0075 & 1.0158 & $0.9362^{* *}$ & $0.6190^{* * *}$ & $0.4368^{* * *}$ \\
\hline Japan & $0.3944 * * *$ & $0.5131^{* * *}$ & $0.6841 * * *$ & $0.8604^{* * *}$ & $0.9617^{* *}$ & $0.9804^{* *}$ & $0.8964^{* * *}$ & $0.7502^{* * *}$ & $0.6319 * * *$ & $0.4648^{* * *}$ & $0.3756^{* * *}$ \\
\hline Korea & $0.4877^{* * *}$ & $0.6492 * * *$ & $0.8064^{* * *}$ & $0.9093 * * *$ & $0.9757^{* *}$ & 0.9971 & 1.0029 & $0.9865^{*}$ & $0.8875^{* * *}$ & $0.6409 * * *$ & $0.4055^{* * *}$ \\
\hline
\end{tabular}




\begin{tabular}{|c|c|c|c|c|c|c|c|c|c|c|c|}
\hline South Africa & 1.2855 & 1.1439 & 1.0534 & 0.9839 & $0.9065^{* *}$ & 1.0774 & $0.9397^{* *}$ & 1.0177 & 1.0196 & 1.0628 & 1.0860 \\
\hline Russia & $0.6867^{* * *}$ & $0.7728^{* * *}$ & $0.8890^{* * *}$ & $0.9548 * * *$ & 0.9983 & 1.0170 & 1.0352 & 1.0502 & 1.0918 & 1.1379 & $0.6841^{* * *}$ \\
\hline Singapore & $0.3824 * * *$ & $0.4810 * * *$ & $0.5966 * * *$ & $0.7920 * * *$ & $0.9389 * *$ & 1.0013 & 1.0189 & 1.0007 & $0.8928 * * *$ & $0.5300 * * *$ & $0.3673^{* * *}$ \\
\hline UK & $0.3759 * * *$ & $0.4671 * * *$ & $0.6010^{* * *}$ & $0.7845^{* * *}$ & $0.9299 * * *$ & 1.0061 & 1.0241 & $0.9547^{* * *}$ & $0.8101 * * *$ & $0.7003 * * *$ & $0.4650 * * *$ \\
\hline
\end{tabular}

Notes: All figures are relative RMSFE (R-RMSFE), i.e., ratios of MSFEs to the MSFE of the historical average benchmark model. A R-RMSFE below unity indicates that the forecasting model over-performs the benchmark forecasting model according to the MSFE metric. *,**, ** denote rejection of the null of equal MSEs according to the McCracken (2007) MSE-F statistic at 10\%, 5\%, and 1\% level of significance, respectively. h-step-ahead forecasts are generated recursively. 
Table 3: Forecasting exchange rate volatility: Forecast evaluation results relative to the historical average benchmark model at various horizons under IVX-QR estimation

Countries

Quantiles

\begin{tabular}{|c|c|c|c|c|c|c|c|c|c|c|c|}
\hline & 0.05 & 0.10 & 0.20 & 0.30 & 0.40 & 0.50 & 0.60 & 0.70 & 0.80 & 0.90 & 0.95 \\
\hline \multicolumn{12}{|c|}{ Panel $A: h=1$ period ahead } \\
\hline Australia & $0.7106^{* * *}$ & $0.8097^{* * *}$ & $0.9193^{* * *}$ & 1.0344 & 1.1820 & 1.1079 & 1.3900 & 1.4970 & 1.6575 & 1.3532 & $0.8287^{* * *}$ \\
\hline Brazil & $0.3262 * * *$ & $0.3503 * * *$ & $0.4767 * * *$ & $0.7777^{* * *}$ & 1.0034 & 1.3590 & 1.7078 & 2.0323 & 1.7724 & 1.1489 & $0.7857^{* * *}$ \\
\hline Canada & $0.5626 * * *$ & $0.7164^{* * *}$ & $0.8419^{* * *}$ & $0.9387^{* * *}$ & 1.1159 & 1.3408 & 1.7027 & 2.1278 & 2.3909 & 1.9051 & 1.2893 \\
\hline Chile & $0.4206 * * *$ & $0.4818^{* * *}$ & $0.6182^{* * *}$ & $0.8471^{* * *}$ & 1.1144 & 1.5010 & 1.9275 & 2.1988 & 2.3643 & 2.2929 & 1.2330 \\
\hline China & $0.3090 * * *$ & $0.3100^{* * *}$ & $0.3131^{* * *}$ & $0.3196^{* * *}$ & $0.3340 * * *$ & $0.3928^{* * *}$ & $0.5096^{* * *}$ & $0.7149 * * *$ & 1.1550 & 1.7399 & 1.5779 \\
\hline EU & 1.0030 & 1.1763 & 1.5698 & 2.0452 & 2.3065 & 2.4461 & 2.3786 & 2.1208 & 1.7671 & 1.1327 & $0.7358^{* * *}$ \\
\hline India & $0.4565 * * *$ & $0.5194^{* * *}$ & $0.6119 * * *$ & $0.8843^{* * *}$ & $0.9794 *$ & 1.4294 & 1.6770 & 1.6936 & 1.6164 & 1.1555 & $0.8931^{* * *}$ \\
\hline Japan & $0.7074 * * *$ & $0.9251^{* * *}$ & 1.4099 & 1.7925 & 2.0845 & 2.3052 & 2.3936 & 2.1655 & 1.5758 & $0.9307^{* * *}$ & $0.5480 * * *$ \\
\hline Korea & $0.6649 * * *$ & $0.7347^{* * *}$ & $0.8605^{* * *}$ & $0.9832 * *$ & 1.0951 & 1.2124 & 1.3157 & 1.4154 & 1.4566 & $0.7327 * * *$ & $0.3525^{* * *}$ \\
\hline South Africa & $0.8021 * * *$ & $0.7311^{* * *}$ & $0.9070^{* * *}$ & 1.0855 & 1.1450 & 1.2494 & 1.3392 & 1.5145 & 1.7103 & 1.8152 & 1.8952 \\
\hline Russia & $0.6554^{* * *}$ & $0.6873^{* * *}$ & $0.7310^{* * *}$ & $0.8046^{* * *}$ & $0.8821 * * *$ & 1.0359 & 1.2681 & 1.5872 & 2.2270 & 2.1947 & $0.5206^{* * *}$ \\
\hline Singapore & $0.6386 * * *$ & $0.7113^{* * *}$ & $0.9409 * * *$ & 1.1348 & 1.3057 & 1.5422 & 1.8266 & 2.1003 & 1.9420 & 1.1154 & $0.9595^{* *}$ \\
\hline UK & $0.8931 * * *$ & $0.9925^{*}$ & 1.1051 & 1.1711 & 1.2210 & 1.3167 & 1.3386 & 1.3489 & 1.2951 & 1.0909 & $0.8979 * * *$ \\
\hline
\end{tabular}

Panel $\mathrm{B}: \mathrm{h}=12$ periods ahead

\begin{tabular}{|c|c|c|c|c|c|c|c|c|c|c|c|}
\hline Australia & $0.6049 * * *$ & $0.6756^{* * *}$ & $0.7749 * * *$ & $0.8564 * * *$ & $0.9565 * * *$ & 1.0592 & 1.0617 & 1.1878 & 1.3509 & 1.1549 & $0.6093^{* * *}$ \\
\hline Brazil & $0.3326^{* * *}$ & $0.3457^{* * *}$ & $0.4382^{* * *}$ & $0.7370^{* * *}$ & $0.9755^{* *}$ & 1.3022 & 1.6583 & 1.8502 & 1.6377 & $0.9117^{* * *}$ & $0.5367^{* * *}$ \\
\hline
\end{tabular}




\begin{tabular}{|c|c|c|c|c|c|c|c|c|c|c|c|}
\hline Canada & $0.5151 * * *$ & $0.6672 * * *$ & $0.7913^{* * *}$ & $0.9125^{* * *}$ & 1.0881 & 1.2764 & 1.5879 & 1.9011 & 2.0675 & 1.6328 & 1.0481 \\
\hline Chile & $0.3787^{* * *}$ & $0.4718^{* * *}$ & $0.6267^{* * *}$ & $0.8839 * * *$ & 1.1579 & 1.5178 & 1.8563 & 1.9688 & 1.9468 & 1.9397 & 1.1577 \\
\hline China & $0.3107^{* * *}$ & $0.3122^{* * *}$ & $0.3152^{* * *}$ & $0.3124 * * *$ & $0.3322^{* * *}$ & $0.3779 * * *$ & $0.4844 * * *$ & $0.6894^{* * *}$ & $0.8771 * * *$ & 1.2005 & 1.0602 \\
\hline EU & 1.0662 & 1.2435 & 1.6506 & 2.1483 & 2.3864 & 2.5238 & 2.5152 & 2.2569 & 1.9287 & 1.2563 & $0.8278^{* * *}$ \\
\hline India & $0.5402 * *$ & $0.6446^{* * *}$ & $0.8100 * * *$ & $1.0487^{* * *}$ & 1.2137 & 1.5994 & 1.7887 & 1.9257 & 1.7195 & 1.2288 & $0.8706^{* * *}$ \\
\hline Japan & $0.9602^{* * *}$ & 1.2898 & 1.3427 & 1.7008 & 1.9664 & 2.1361 & 2.2726 & 2.0212 & 1.5125 & 1.0362 & $0.6667^{* * *}$ \\
\hline Korea & $0.6579 * * *$ & $0.7263^{* * *}$ & $0.8432 * * *$ & $0.9517^{* * *}$ & 1.0575 & 1.1604 & 1.2700 & 1.3448 & 1.3371 & $0.6794 * * *$ & $0.3774^{* * *}$ \\
\hline South Africa & $0.8522^{* * *}$ & $0.9249 * *$ & 0.9985 & 1.0236 & 1.0275 & 1.0862 & 1.2018 & 1.2949 & 1.4262 & 1.5256 & 1.4789 \\
\hline Russia & $0.6743^{* * *}$ & $0.7033^{* * *}$ & $0.7427^{* * *}$ & $0.8046^{* * *}$ & $0.8815^{* * *}$ & 0.9943 & 1.2176 & 1.5094 & 2.0033 & 2.4022 & $0.5707^{* * *}$ \\
\hline Singapore & $0.8612^{* * *}$ & $0.9705^{* *}$ & 1.0223 & 1.1625 & 1.3618 & 1.8865 & 2.0925 & 2.1865 & 2.0688 & 1.4387 & 1.3882 \\
\hline UK & 1.0165 & 1.1583 & 1.3435 & 1.4816 & 1.6047 & 1.7688 & 1.8498 & 1.8686 & 1.7538 & 1.2752 & 0.9839* \\
\hline
\end{tabular}

Panel $\mathrm{C}: \mathrm{h}=24$ periods ahead ( 8 for SA)

\begin{tabular}{|c|c|c|c|c|c|c|c|c|c|c|c|}
\hline Australia & $0.5260 * * *$ & $0.5844 * * *$ & $0.6178^{* * *}$ & $0.7271^{* * *}$ & $0.8539 * * *$ & $0.9515^{* * *}$ & $0.9813^{* *}$ & 0.9952 & 1.1482 & 0.9442 & $0.5480^{* * *}$ \\
\hline Brazil & $0.3294 * * *$ & $0.3476^{* * *}$ & $0.5248^{* * *}$ & $0.8329 * * *$ & 1.0774 & 1.3423 & 1.5709 & 1.6043 & 1.2956 & $0.7319^{* * *}$ & $0.4135^{* * *}$ \\
\hline Canada & $0.4822^{* * *}$ & $0.6281^{* * *}$ & $0.7403^{* * *}$ & $0.8786^{* * *}$ & 1.0192 & 1.1882 & 1.4399 & 1.6521 & 1.7700 & 1.3243 & $0.8826^{* * *}$ \\
\hline Chile & $0.3730 * * *$ & $0.4304 * * *$ & $0.5431 * * *$ & $0.7004^{* * *}$ & 0.8729 & 1.1209 & 1.3254 & 1.4729 & 1.5600 & 1.3426 & $0.8164^{* * *}$ \\
\hline China & $0.3121 * * *$ & $0.3135^{* * *}$ & $0.3165^{* * *}$ & $0.3227 * * *$ & $0.3316^{* * *}$ & $0.3662^{* * *}$ & $0.4586 * * *$ & $0.6604 * * *$ & $0.9843^{*}$ & 1.2494 & 1.0254 \\
\hline EU & 1.0855 & 1.2701 & 1.6817 & 2.1624 & 2.4109 & 2.5846 & 2.5516 & 2.3107 & 1.9935 & 1.3355 & $0.7836 * * *$ \\
\hline India & $0.4950 * * *$ & $0.5787^{* * *}$ & $0.7610^{* * *}$ & $0.9576^{* *}$ & 1.2637 & 1.5643 & 1.7377 & 1.8030 & 1.9237 & 1.3822 & 1.0511 \\
\hline Japan & $0.9757^{* *}$ & 1.2875 & 1.2917 & 1.4077 & 1.7924 & 2.0290 & 2.0867 & 1.7937 & 1.0959 & 0.9938 & $0.6707^{* * *}$ \\
\hline Korea & $0.7454^{* * *}$ & $0.8124 * * *$ & $0.9180 * * *$ & 0.9994 & 1.0272 & 1.1190 & 1.2403 & 1.3111 & 1.3209 & 0.9937 & $0.7687^{* * *}$ \\
\hline
\end{tabular}




\begin{tabular}{|c|c|c|c|c|c|c|c|c|c|c|c|}
\hline South Africa & $0.7989 * * *$ & $0.7929 * * *$ & $0.8761 * * *$ & 0.9901 & 1.0158 & 1.1414 & 1.4884 & 1.7018 & 1.8349 & 1.8017 & 1.7302 \\
\hline Russia & $0.8725^{* * *}$ & $0.9007 * * *$ & 1.0378 & 1.0900 & 1.0933 & 1.1200 & 1.1732 & 1.4435 & 1.9595 & 2.5128 & $0.8601 * * *$ \\
\hline Singapore & $0.8652^{* * *}$ & $0.9848^{*}$ & 1.0777 & 1.1825 & 1.4047 & 1.7566 & 2.0318 & 2.1133 & 2.0663 & 1.3325 & 1.1760 \\
\hline UK & 1.0454 & 1.2064 & 1.4632 & 1.5848 & 1.7756 & 1.9195 & 1.9808 & 2.0307 & 1.8504 & 1.5034 & 1.0952 \\
\hline
\end{tabular}

Notes: All figures are relative RMSFE (R-RMSFE), i.e., ratios of MSFEs to the MSFE of the historical average benchmark model. A R-RMSFE below unity indicates that the forecasting model over-performs the benchmark forecasting model according to the MSFE metric. *,**, ** denote rejection of the null of equal MSEs according to the McCracken (2007) MSE-F statistic at 10\%, 5\%, and 1\% level of significance, respectively. h-step-ahead forecasts are generated recursively. 


\section{$\underline{\text { Appendix }}$}

Table A1. Summary Statistics

\begin{tabular}{|c|c|c|c|c|c|c|c|c|c|c|}
\hline & \multicolumn{8}{|c|}{ Exchange Rate Return } & \multicolumn{2}{|c|}{ EPU } \\
\hline Country & Mean & Std.Dev & Skewness & Kurtosisi & $\mathrm{J}-\mathrm{B}$ & $\mathrm{p}$-value & Start & End & Mean & Std.Dev \\
\hline Australia & 0.0003 & 0.0347 & -0.6723 & 6.5585 & 165.81 & 0.0000 & $29 / 1 / 1994$ & $29 / 11 / 2016$ & -0.2332 & 0.3727 \\
\hline Brazil & 0.0048 & 0.0551 & 3.4951 & 34.3843 & 11544.53 & 0.0000 & 29/8/1994 & $29 / 11 / 2016$ & -0.0441 & 0.5647 \\
\hline Canada & 0.0001 & 0.0246 & 1.1020 & 11.8337 & 946.35 & 0.0000 & $28 / 2 / 1994$ & $29 / 11 / 2016$ & 0.0282 & 0.3844 \\
\hline Chile & 0.0016 & 0.0304 & 0.9588 & 7.9729 & 324.32 & 0.0000 & 28/2/1994 & $29 / 11 / 2016$ & -0.1165 & 0.4193 \\
\hline China & -0.0009 & 0.0048 & 0.8646 & 11.3754 & 834.99 & 0.0000 & 28/2/1994 & $29 / 11 / 2016$ & -0.0397 & 0.5425 \\
\hline $\mathrm{EU}$ & 0.0001 & 0.0299 & 0.1777 & 4.2475 & 25.45 & 0.0000 & 29/9/1986 & $29 / 11 / 2016$ & 0.0444 & 0.3497 \\
\hline India & 0.0029 & 0.0206 & 0.7769 & 8.6897 & 397.16 & 0.0000 & $28 / 2 / 1994$ & $29 / 11 / 2016$ & -0.2526 & 0.4349 \\
\hline Japan & 0.0001 & 0.0307 & -0.3200 & 4.7574 & 39.93 & 0.0000 & $28 / 2 / 1994$ & $29 / 11 / 2016$ & -0.0796 & 0.3525 \\
\hline Korea & 0.0013 & 0.0380 & 1.0868 & 12.4424 & 1071.84 & 0.0000 & 28/2/1994 & $29 / 11 / 2016$ & -0.1429 & 0.4164 \\
\hline South Africa & 0.0154 & 0.0766 & 0.5296 & 4.6081 & 42.33 & 0.0000 & 28/2/1994 & $29 / 11 / 2016$ & -1.5938 & 0.7471 \\
\hline Russia & 0.0105 & 0.0573 & 5.5921 & 53.0737 & 27202.07 & 0.0000 & 29/4/1996 & $29 / 11 / 2016$ & -0.0539 & 0.7454 \\
\hline Singapore & -0.0013 & 0.0174 & 0.7024 & 6.6462 & 108.78 & 0.0000 & 37623.0000 & $29 / 11 / 2016$ & -0.0449 & 0.2246 \\
\hline \multirow[t]{2}{*}{ UK } & 0.0005 & 0.0282 & 0.6454 & 4.8526 & 77.11 & 0.0000 & 29/9/1986 & $29 / 11 / 2016$ & 0.1032 & 0.5422 \\
\hline & \multicolumn{6}{|c|}{ Realized Volatility } & & & & \\
\hline Australia & 0.0070 & 0.0033 & 3.0514 & 18.7774 & 3255.1870 & 0.0000 & & & & \\
\hline Brazil & 0.0079 & 0.0055 & 1.5312 & 7.4763 & 329.6918 & 0.0000 & & & & \\
\hline Canada & 0.0048 & 0.0023 & 1.6445 & 8.0446 & 415.5452 & 0.0000 & & & & \\
\hline Chile & 0.0053 & 0.0025 & 1.4340 & 7.2542 & 301.6301 & 0.0000 & & & & \\
\hline China & 0.0009 & 0.0053 & 16.1327 & 265.0729 & 798912.2000 & 0.0000 & & & & \\
\hline EU & 0.0059 & 0.0018 & 1.0772 & 5.8393 & 192.1304 & 0.0000 & & & & \\
\hline India & 0.0029 & 0.0021 & 1.0009 & 3.8701 & 54.5942 & 0.0000 & & & & \\
\hline Japan & 0.0064 & 0.0023 & 1.1328 & 5.0385 & 106.4274 & 0.0000 & & & & \\
\hline Korea & 0.0058 & 0.0064 & 6.2365 & 58.4392 & 36999.8900 & 0.0000 & & & & \\
\hline South Africa & 0.0087 & 0.0043 & 0.8787 & 5.3131 & 32.3498 & 0.0000 & & & & \\
\hline Russia & 0.0072 & 0.0143 & 6.6671 & 56.0588 & 31052.7300 & 0.0000 & & & & \\
\hline Singapore & 0.0033 & 0.0013 & 1.5024 & 6.2350 & 138.8933 & 0.0000 & & & & \\
\hline UK & 0.0056 & 0.0021 & 2.4903 & 15.5323 & 2750.7120 & 0.0000 & & & & \\
\hline
\end{tabular}




\begin{tabular}{l|cccccccc|cc}
\hline & \multicolumn{7}{|c}{ Exchange Rate Return } & \multicolumn{2}{c}{ EPU } \\
\hline Country & Mean & Std.Dev & Skewness & Kurtosisi & J-B & p-value & Start & End & Mean & Std.Dev \\
\hline Australia & 0.0003 & 0.0347 & -0.6723 & 6.5585 & 165.81 & 0.0000 & $29 / 1 / 1994$ & $29 / 11 / 2016$ & -0.2332 & 0.3727 \\
Brazil & 0.0048 & 0.0551 & 3.4951 & 34.3843 & 11544.53 & 0.0000 & $29 / 8 / 1994$ & $29 / 11 / 2016$ & -0.0441 & 0.5647 \\
Canada & 0.0001 & 0.0246 & 1.1020 & 11.8337 & 946.35 & 0.0000 & $28 / 2 / 1994$ & $29 / 11 / 2016$ & 0.0282 & 0.3844 \\
Chile & 0.0016 & 0.0304 & 0.9588 & 7.9729 & 324.32 & 0.0000 & $28 / 2 / 1994$ & $29 / 11 / 2016$ & -0.1165 & 0.4193 \\
China & -0.0009 & 0.0048 & 0.8646 & 11.3754 & 834.99 & 0.0000 & $28 / 2 / 1994$ & $29 / 11 / 2016$ & -0.0397 & 0.5425 \\
EU & 0.0001 & 0.0299 & 0.1777 & 4.2475 & 25.45 & 0.0000 & $29 / 9 / 1986$ & $29 / 11 / 2016$ & 0.0444 & 0.3497 \\
India & 0.0029 & 0.0206 & 0.7769 & 8.6897 & 397.16 & 0.0000 & $28 / 2 / 1994$ & $29 / 11 / 2016$ & -0.2526 & 0.4349 \\
Japan & 0.0001 & 0.0307 & -0.3200 & 4.7574 & 39.93 & 0.0000 & $28 / 2 / 1994$ & $29 / 11 / 2016$ & -0.0796 & 0.3525 \\
Korea & 0.0013 & 0.0380 & 1.0868 & 12.4424 & 1071.84 & 0.0000 & $28 / 2 / 1994$ & $29 / 11 / 2016$ & -0.1429 & 0.4164 \\
South & & & & & & & & & & \\
Africa & 0.0154 & 0.0766 & 0.5296 & 4.6081 & 42.33 & 0.0000 & $28 / 2 / 1994$ & $29 / 11 / 2016$ & -1.5938 & 0.7471 \\
Russia & 0.0105 & 0.0573 & 5.5921 & 53.0737 & 27202.07 & 0.0000 & $29 / 4 / 1996$ & $29 / 11 / 2016$ & -0.0539 & 0.7454 \\
Singapore & -0.0013 & 0.0174 & 0.7024 & 6.6462 & 108.78 & 0.0000 & 37623.0000 & $29 / 11 / 2016$ & -0.0449 & 0.2246 \\
UK & 0.0005 & 0.0282 & 0.6454 & 4.8526 & 77.11 & 0.0000 & $29 / 9 / 1986$ & $29 / 11 / 2016$ & 0.1032 & 0.5422 \\
\hline
\end{tabular}


Table A2: Unit Root and Endogeneity Test Results.

\begin{tabular}{|c|c|c|c|c|c|c|c|c|c|}
\hline \multirow[t]{3}{*}{ Countries } & \multicolumn{3}{|c|}{ Unit Root Tests } & \multicolumn{6}{|c|}{ Endogeneity Test } \\
\hline & & & & & Model 1 & & & Model 2 & \\
\hline & $A D F(A I C)$ & ADF(MAIC) & KPSS & Coefficient & t-stat & p-value & Coefficient & t-stat & p-value \\
\hline Australia & $-2.8073 * *$ & $-2.2979 * * *$ & $0.5458 * *$ & -0.0200 & -2.8286 & 0.0051 & 0.0019 & 2.9786 & 0.0032 \\
\hline Brazil & $-3.0722 *$ & $-1.5215 * * *$ & $0.9688 * * *$ & 0.0194 & 2.7744 & 0.0059 & 0.0018 & 2.7686 & 0.0060 \\
\hline Canada & $-2.0118 * * *$ & $-2.0118 * * *$ & $0.5331 * *$ & 0.0082 & 1.6107 & 0.1084 & 0.0004 & 0.8647 & 0.3879 \\
\hline Chile & $-3.1490^{*}$ & $-1.9452 * * *$ & $0.3611 *$ & 0.0129 & 2.3923 & 0.0174 & -0.0008 & -1.7454 & 0.0820 \\
\hline China & -3.7125 & $-2.7302 * *$ & 1.0089 *** & -0.0001 & -0.2671 & 0.7896 & 0.0003 & 3.7640 & 0.0002 \\
\hline EU & $-2.8097 * *$ & $-1.5895 * * *$ & $1.3399 * * *$ & 0.0009 & 1.2147 & 0.2255 & -0.0005 & -1.3410 & 0.1801 \\
\hline India & $-3.3544 *$ & $-1.9338 * * *$ & 0.3083 & 0.0102 & 1.9740 & 0.0501 & 0.0008 & 2.2219 & 0.0277 \\
\hline Japan & -7.1873 & $-2.1565 * * *$ & $0.6153 * *$ & 0.0052 & 0.8590 & 0.3911 & 0.0003 & 0.6525 & 0.5146 \\
\hline Korea & -4.1766 & $-2.4727 * * *$ & $1.0760 * * *$ & 0.0009 & 1.2147 & 0.2255 & 0.0009 & 0.7369 & 0.4618 \\
\hline Russia & $-3.0488^{*}$ & $-2.7488 * *$ & $0.5612 * *$ & 0.0016 & 0.2682 & 0.7888 & 0.0008 & 0.4934 & 0.6221 \\
\hline Singapore & -3.6118 & $-2.3918 * * *$ & $0.9205^{* * *}$ & 0.0084 & 1.1960 & 0.2334 & -0.0001 & -0.2654 & 0.7910 \\
\hline $\begin{array}{l}\text { South } \\
\text { Africa }\end{array}$ & -4.7142 & $-1.9843 * * *$ & $0.34810^{*}$ & 0.0112 & 0.9894 & 0.3252 & 0.0007 & 1.1114 & 0.2694 \\
\hline UK & $-0.2220 * * *$ & $-0.2220 * * *$ & $1.0106 * * *$ & 0.0061 & 1.2137 & 0.2261 & 0.0003 & 0.7193 & 0.4726 \\
\hline
\end{tabular}

Notes: $*, * * * * *$ denote acceptance of the unit root hypothesis at $10 \%, 5 \%$, and $1 \%$ level of significance, respectively. p-value refers to the non-endogeneity null hypothesis of the endogeneity test suggested by Narayan and Gupta (2015). Model 1: $R_{t}=\alpha_{1, \tau}+\beta_{1, \tau} E P U_{t-1}+u_{t}$. Model 2: $V_{t}=\alpha_{2, \tau}+\beta_{2, \tau} E P U_{t-1}+u_{t}$. 
Table A3: Forecasting exchange rate returns: Forecast evaluation results relative to the historical average benchmark model at various horizons under conventional QR estimation

Countries

0.05

Panel A: h=1 period ahead

\begin{tabular}{|c|c|c|c|c|c|c|c|c|c|c|c|}
\hline & 0.05 & 0.10 & 0.20 & 0.30 & 0.40 & 0.50 & 0.60 & 0.70 & 0.80 & 0.90 & 0.95 \\
\hline \multicolumn{12}{|c|}{ Panel A: $\mathrm{h}=1$ period ahead } \\
\hline Australia & 1.1929 & 1.2255 & 1.1252 & 1.0907 & 1.0349 & 1.0111 & 1.0022 & $0.9593^{* * *}$ & 1.0043 & 1.0460 & 1.1086 \\
\hline Brazil & $0.9484 * * *$ & 1.0562 & 1.0981 & 1.0519 & 1.0119 & 1.0098 & 1.0001 & 1.0395 & 1.1281 & 1.2160 & 1.1947 \\
\hline Canada & $0.8606 * * *$ & $0.8650 * * *$ & $0.9505^{* * *}$ & $0.9714 * *$ & $0.9899 *$ & 0.9976 & 0.9978 & 1.0033 & $0.9940 *$ & 0.9988 & 1.0390 \\
\hline Chile & 1.0388 & 1.0589 & 1.1438 & 1.0992 & 1.0226 & 0.9985 & $0.9815^{* *}$ & $0.9789 * *$ & $0.9173^{* * *}$ & $0.9634 * * *$ & $0.8887 * * *$ \\
\hline China & 1.1707 & 1.1103 & 1.1059 & 1.0266 & 1.0038 & 0.9989 & 0.9994 & 0.9973 & $0.9878^{*}$ & $0.9671^{* * *}$ & $0.9765^{* *}$ \\
\hline EU & $0.8622 * * *$ & $0.9309^{* * *}$ & $0.9355^{* * *}$ & $0.9758^{* * *}$ & 1.0098 & 1.0083 & $0.9938^{*}$ & 1.0102 & $0.9861 * *$ & 1.0122 & $0.9925^{*}$ \\
\hline India & 1.3581 & 1.0913 & 0.9988 & 1.0070 & 1.0028 & 0.9938 & 1.0066 & 1.0235 & 1.0137 & 1.2558 & $0.9465^{* * * *}$ \\
\hline Japan & 1.0810 & 1.0446 & 1.0755 & 1.0614 & 1.0546 & 1.0292 & 1.0100 & 1.0143 & 1.0140 & $0.9930 *$ & 1.0131 \\
\hline Korea & 0.9950 & 1.0279 & 1.0227 & 1.0149 & 1.0042 & 1.0002 & 1.004 & 1.0085 & 1.0009 & 1.0999 & 1.3101 \\
\hline South Africa & 1.0977 & 1.2617 & 0.9889 & 1.0224 & 1.0073 & 1.0776 & 1.0501 & 1.0052 & 1.0149 & 1.1099 & 1.0866 \\
\hline Russia & 1.0009 & 0.9953 & 1.0056 & 1.0027 & 1.0021 & 1.0035 & 1.0003 & 0.9997 & 1.0173 & 1.01010 & 1.0856 \\
\hline Singapore & 1.1482 & 1.0109 & $0.9144 * * *$ & 1.0115 & $0.9595 * *$ & 1.0055 & 1.0444 & 1.0784 & 1.0309 & 1.0618 & 1.0958 \\
\hline UK & 1.0520 & 1.1011 & 1.0482 & 1.0717 & 1.0626 & 1.0169 & 1.0036 & $0.9647 * * *$ & $0.9398 * * *$ & 1.1218 & 1.2935 \\
\hline
\end{tabular}

Panel B: $\mathrm{h}=12$ periods ahead ( 4 quarters in the case of South Africa)

$\begin{array}{llllllrrrrrrr}\text { Australia } & 1.1075 & 1.0824 & 1.0296 & 1.0059 & 0.9946 & 0.9938 & 0.9703 * * & 0.9922 & 1.0266 & 0.9955 & 1.1226 \\ \text { Brazil } & 1.0078 & 1.0109 & 1.0509 & 1.0532 & 1.0663 & 1.0375 & 1.0050 & 1.0065 & 1.0492 & 1.0380 & 1.0191\end{array}$

Quantiles 


\begin{tabular}{|c|c|c|c|c|c|c|c|c|c|c|c|}
\hline Canada & $0.9184 * * *$ & $0.9349 * * *$ & $0.9922 *$ & $0.9920^{*}$ & 1.0016 & 1.0016 & 1.0036 & 1.0005 & 1.0202 & $0.9883^{*}$ & $0.9912 *$ \\
\hline Chile & 1.1093 & 1.1325 & 1.0907 & 1.1673 & 1.0505 & 1.0203 & 0.9953 & $0.9494 * * *$ & $0.8948 * * *$ & 1.0395 & 1.0174 \\
\hline China & 1.1954 & 1.0014 & 1.0323 & 1.0019 & 0.9951 & 0.9998 & 0.9995 & 0.9999 & 0.9995 & 1.0045 & 1.0146 \\
\hline EU & 1.0239 & $0.9646 * * *$ & $0.9921 *$ & 1.000 & 1.0086 & 1.0134 & $0.9946^{*}$ & $0 . .9977$ & $0.9631 * * *$ & $0.9163^{* * *}$ & $0.9895^{*}$ \\
\hline India & 1.2413 & $0.9523 * *$ & 0.9943 & $0.9625^{* *}$ & 0.9896 & 0.9940 & 0.9902 & 1.0084 & 1.0251 & 1.0113 & $0.8853 * * *$ \\
\hline Japan & 1.0075 & 1.0433 & $0.9871 *$ & 1.0053 & 1.0116 & 1.0170 & 1.0139 & $0.9919 *$ & 1.0110 & $0.9832 * *$ & 1.0131 \\
\hline Korea & 1.0574 & 1.0426 & 1.0479 & 1.0099 & 1.0025 & 1.0011 & 1.0008 & $0.9896^{*}$ & $0.9721 * *$ & 0.8495 & 0.9446 \\
\hline South Africa & 1.1219 & 1.5283 & 1.0608 & 1.0486 & 1.0391 & 1.1812 & $0.9711^{*}$ & $0.9516^{* *}$ & 1.0300 & 0.9797 & 0.9881 \\
\hline Russia & 1.0427 & 1.0407 & 1.0372 & 1.0062 & 1.0052 & 1.0026 & 1.0006 & 1.0015 & 1.0152 & 1.0053 & 1.0746 \\
\hline Singapore & 1.0494 & 0.9951 & $0.9337 * * *$ & 0.9961 & 1.0056 & 0.9954 & 1.0028 & 1.0127 & 1.0325 & 1.1608 & 1.1337 \\
\hline UK & 1.0252 & 0.9971 & 1.0808 & 1.1038 & 1.0795 & 1.0050 & 1.0083 & $0.9689 * *$ & $0.9911^{*}$ & 1.1126 & 1.1771 \\
\hline \multicolumn{12}{|c|}{ Panel C: h-24 periods ahead ( 8 quarters in the case of South Africa) } \\
\hline Australia & 1.1949 & 1.0218 & 1.0035 & 1.0404 & 1.0114 & 1.0025 & 1.0028 & $0.9812 *$ & $0.9440 * * *$ & $0.9488^{* * *}$ & $0.9546^{* * *}$ \\
\hline Brazil & 1.0118 & 0.9946 & 1.0150 & 1.0149 & $0.9853^{*}$ & 1.0015 & 1.0039 & 1.0081 & 1.1237 & 1.2457 & 1.1682 \\
\hline Canada & $0.9917^{*}$ & 1.0079 & $0.9526 * * *$ & $0.9665^{* * *}$ & $0.9920^{*}$ & $0.9841 * *$ & 0.9982 & $0.9645^{* * *}$ & 0.9910* & 0.9976 & 1.0338 \\
\hline Chile & 1.0781 & 1.1844 & 1.0955 & 1.1002 & 1.0492 & $0.9854 *$ & $0.9559 * * *$ & $0.9171 * * *$ & $0.8150 * * *$ & $0.8530 * * *$ & $0.8914 * * *$ \\
\hline China & 1.2243 & 1.3442 & 1.0275 & 0.9948 & 0.9980 & 1.0000 & 0.9995 & 0.9999 & 0.9997 & 1.0074 & 1.0393 \\
\hline EU & $0.9185^{* * *}$ & $0.9597 * * *$ & 0.9999 & 0.9964 & 0.9947 & 0.9966 & 1.0067 & 0.9961 & 1.0061 & $0.9823 * *$ & 0.9959 \\
\hline India & 0.9938 & 1.0150 & 1.0269 & 1.0169 & 1.0194 & 1.0025 & 1.0146 & 1.0193 & 1.1233 & 1.0698 & 1.0601 \\
\hline Japan & $0.9303 * * *$ & $0.9710^{* *}$ & 1.0186 & 1.0194 & 1.0017 & 1.0174 & 1.0036 & 1.0080 & 1.0182 & 1.0011 & 1.0361 \\
\hline Korea & $0.9886^{*}$ & 1.0198 & 1.0229 & 1.0050 & 1.0094 & 1.0031 & 0.9989 & $0.9928^{*}$ & 0.9974 & 1.0541 & 1.2422 \\
\hline
\end{tabular}




\begin{tabular}{|c|c|c|c|c|c|c|c|c|c|c|c|}
\hline South Africa & 1.1649 & 1.4287 & 1.0287 & 1.0070 & 1.0664 & 1.1823 & 1.0616 & 1.0014 & 0.9908 & 0.9903 & 0.9801 \\
\hline Russia & 1.0294 & 1.0179 & 1.0226 & 1.0016 & 0.9973 & 1.0005 & 0.9961 & 1.0038 & 1.0565 & 1.6376 & 1.3402 \\
\hline Singapore & 1.0871 & 1.0675 & $0.9442 * *$ & 1.0045 & 1.0050 & 1.0179 & 1.0210 & 1.0657 & 1.0640 & 1.1821 & 1.1111 \\
\hline UK & $0.8994 * * *$ & $0.9035 * * *$ & $0.8612 * * *$ & $0.8990 * * *$ & $0.9478 * * *$ & 0.9962 & 1.0521 & 1.0681 & 1.1253 & 1.5020 & 1.2074 \\
\hline
\end{tabular}

Notes: All figures are relative RMSFE (R-RMSFE), i.e., ratios of MSFEs to the MSFE of the historical average benchmark model. A R-RMSFE below unity indicates that the forecasting model over-performs the benchmark forecasting model according to the MSFE metric. *,**,** denote rejection of the null of equal MSEs according to the McCracken (2007) MSE-F statistic at 10\%,5\%, and 1\% level of significance, respectively. h-step-ahead forecasts are generated recursively. 
Table A4: Forecasting exchange rate volatility: Forecast evaluation results relative to the historical average benchmark model at various horizons under conventional QR estimation

Countries

$\begin{array}{llllllllllll}0.05 & 0.10 & 0.20 & 0.30 & 0.40 & 0.50 & 0.60 & 0.70 & 0.80 & 0.90 & 0.95\end{array}$

Panel A: h=1 period ahead

\begin{tabular}{|c|c|c|c|c|c|c|c|c|c|c|c|}
\hline Australia & $0.9639 * *$ & $0.9607 * * *$ & $0.9156^{* * *}$ & $0.9178 * * *$ & $0.9243 * * *$ & $0.9408 * * *$ & $0.9587 * * *$ & 1.0171 & 1.1125 & 1.3229 & 1.4656 \\
\hline Brazil & $0.9421 * * *$ & $0.8429 * * *$ & $0.7822 * * *$ & $0.9468 * * *$ & $0.9039 * * *$ & $0.9169 * * *$ & $0.9300 * * *$ & $0.9452 * * *$ & 1.0560 & 1.1437 & 1.6893 \\
\hline Canada & $0.9306 * * *$ & 1.0388 & 1.0380 & 1.0375 & 1.0766 & 1.0513 & 1.0499 & 1.0942 & 1.1084 & 1.3055 & 1.3976 \\
\hline Chile & 1.0058 & 1.0061 & 1.0151 & $0.9623 * * *$ & $0.9059 * * *$ & $0.9212 * * *$ & $0.9815^{* *}$ & 0.9929 & 1.0849 & 1.4605 & 1.5262 \\
\hline China & 0.9990 & 0.9986 & $0.9916^{*}$ & $0.9779 * *$ & $0.9170 * * *$ & $0.8558 * * *$ & $0.8515^{* * *}$ & 0.8593 *** & $0.8703 * * *$ & $0.9848 * * *$ & $0.9623^{* * * *}$ \\
\hline EU & 1.0420 & 1.0551 & 1.0405 & 1.0957 & 1.0583 & 1.0022 & $0.9567 * * *$ & $0.9428 * * *$ & $0.9142 * * *$ & $0.8579 * * *$ & 0.8383 *** \\
\hline India & $0.8503 * * *$ & $0.8303^{* * *}$ & $0.8047 * * *$ & $0.6874 * * *$ & $0.7099 * * *$ & $0.7379 * * *$ & $0.8838 * * *$ & $0.8207 * * *$ & $0.8500 * * *$ & $0.9045^{* * *}$ & 1.0151 \\
\hline Japan & $0.9471 * * *$ & $0.9633^{* * *}$ & 1.0325 & 1.0024 & 1.0117 & 1.0152 & 1.0230 & 1.0382 & 1.0577 & $0.9820 * *$ & $0.9001 * * *$ \\
\hline Korea & $0.9202 * * *$ & $0.9274 * * *$ & $0.9478 * * *$ & $0.9838 * *$ & $0.9922^{*}$ & $0.9846 * *$ & 0.9942 & 0.9997 & 1.0482 & 1.0592 & 1.2196 \\
\hline South Africa & 1.0490 & 1.0269 & 1.0161 & 1.0140 & 1.1444 & 1.0914 & 1.0585 & 1.1497 & 1.1392 & 1.2310 & 1.1210 \\
\hline Russia & 0.9943 & 0.9984 & $0.9824 * *$ & $0.9758 * *$ & $0.9827 * *$ & $0.9756^{* *}$ & $0.9656 * * *$ & $0.9784 * *$ & 1.0401 & 1.5932 & $0.5988^{* * *}$ \\
\hline Singapore & $0.9418 * *$ & $0.8800 * * *$ & $0.9308 * * *$ & $0.9425 * * *$ & $0.9367 * * *$ & $0.9469 * * *$ & 0.9948 & 1.0243 & 1.0221 & 1.0434 & $0.9794 *$ \\
\hline UK & $0.9462 * * *$ & $0.9740 * *$ & $0.9927^{*}$ & $0.9772 * *$ & $0.9912 *$ & $0.9910^{*}$ & 0.9935 & 1.0269 & 1.1039 & 1.3698 & 1.1657 \\
\hline
\end{tabular}

Panel B: $\mathrm{h}=12$ periods ahead ( 4 quarters in the case fof South Africa)

\begin{tabular}{|c|c|c|c|c|c|c|c|c|c|c|c|}
\hline Australia & $0.9757 * *$ & $0.9546^{* * *}$ & $0.9724 * *$ & $0.9718^{* *}$ & $0.9845^{* *}$ & 0.9942 & 1.0064 & 1.0173 & 1.0380 & 1.1713 & 1.0973 \\
\hline Brazil & $0.9696^{* *}$ & $0.8810^{* * *}$ & $0.7810 * * *$ & $0.8872 * * *$ & $0.9343^{* * *}$ & $0.9776^{* *}$ & 1.0088 & $0.9694^{* *}$ & 1.0003 & 0.9979 & 1.0395 \\
\hline
\end{tabular}




\begin{tabular}{|c|c|c|c|c|c|c|c|c|c|c|c|}
\hline Canada & $0.8741^{* * *}$ & 0.9972 & 0.9967 & 0.9938 & 1.0151 & $0.9518 * * *$ & $0.9739 * *$ & $0.9851^{* *}$ & $0.9451 * * *$ & $0.8703 * * *$ & $0.6289 * * *$ \\
\hline Chile & 0.9957 & 1.0191 & $0.9381 * * *$ & $0.8404^{* * * *}$ & $0.8519 * * *$ & $0.9255^{* * *}$ & $0.9515^{* * *}$ & $0.9895^{*}$ & 1.0238 & 1.5209 & 1.1743 \\
\hline China & 1.0002 & 1.0004 & 0.987 & 0.9958 & $0.9883^{*}$ & $0.9724 * *$ & 0.9974 & 1.0039 & 1.0157 & 1.1129 & 1.0966 \\
\hline EU & 1.0606 & 1.0191 & 1.0439 & 1.0767 & 1.0521 & 1.0120 & $0.9613 * * *$ & $0.9352 * * *$ & $0.9540 * * *$ & $0.8318^{* * *}$ & $0.7867 * * *$ \\
\hline India & $0.8617 * * *$ & $0.9240 * * *$ & $0.8559 * * *$ & $0.7792 * * *$ & $0.8848 * * *$ & $0.9151 * * *$ & 1.0132 & 1.0485 & 1.1499 & 1.0152 & 1.2630 \\
\hline Japan & 1.0051 & 1.0017 & 1.0055 & $0.9885^{*}$ & 1.0168 & 1.0133 & 1.0177 & 1.0182 & 1.0112 & $0.8129 * * *$ & $0.9022 * * *$ \\
\hline Korea & $0.9764 * *$ & $0.9461^{* * *}$ & $0.9738 * *$ & 1.0107 & 1.0055 & 0.9995 & 1.0011 & 0.9981 & $0.9877 *$ & $0.8231 * * *$ & $0.7639 * * *$ \\
\hline South Africa & 0.9928 & $0.8922 * * *$ & $0.8293^{* * *}$ & $0.9110^{* *}$ & 1.0441 & $0.9491^{*}$ & 0.9939 & $0.9382 * *$ & 1.0574 & $0.7875^{* * *}$ & 1.2936 \\
\hline Russia & 0.9969 & $0.9871^{*}$ & $0.9687 * *$ & $0.9714 * *$ & $0.9681 * *$ & $0.9785^{* *}$ & $0.9674 * *$ & $0.9691 * *$ & $0.9502 * * *$ & $0.9830 * *$ & $0.8735 * * *$ \\
\hline Singapore & $0.9868^{*}$ & 0.9929 & 1.0226 & 1.0066 & 1.0065 & 1.0262 & 1.0334 & 1.0218 & 0.9963 & 0.9998 & 1.0110 \\
\hline UK & $0.9539 * * *$ & $0.9586^{* * *}$ & $0.9734 * *$ & $0.9744 * *$ & $0.9734 * *$ & $0.9840^{*}$ & 1.0294 & 1.0959 & 1.2395 & 1.2948 & 1.7903 \\
\hline
\end{tabular}

Panel C: $\mathrm{h}=24$ periods ahead ( 8 quarters in the case of South Africa )

\begin{tabular}{|c|c|c|c|c|c|c|c|c|c|c|c|}
\hline Australia & $0.9781 * *$ & $0.9812 *$ & 0.9912 & $0.9856^{*}$ & 1.0173 & 1.0035 & $0.9858^{*}$ & 1.0098 & $0.9338 * * *$ & $0.9049^{* * *}$ & 1.1282 \\
\hline Brazil & $0.9585^{* * *}$ & $0.7936^{* * *}$ & $0.7772 * * *$ & $0.9207 * * *$ & $0.8393 * * *$ & $0.9106^{* * *}$ & $0.9715^{* *}$ & 0.9896* & 1.0740 & $0.9905^{*}$ & $0.8983 * * *$ \\
\hline Canada & $0.8741 * * *$ & 1.0287 & $0.9797 * *$ & 1.0014 & $0.9789 * *$ & $0.9488^{* * *}$ & $0.9608 * * *$ & $0.9857^{*}$ & $0.9755^{* *}$ & $0.9089 * * *$ & $0.8823^{* * *}$ \\
\hline Chile & 1.0117 & 1.0507 & 1.0612 & 1.0714 & 1.0356 & 1.0330 & 1.0239 & 1.0088 & $0.9661^{* *}$ & 0.9951 & $0.7905^{* * *}$ \\
\hline China & 0.9979 & 0.9987 & 0.9961 & 0.9956 & 0.9922 & $0.9581 * * *$ & $0.8487 * * *$ & $0.9632 * *$ & 0.9928 & 1.0591 & 1.0534 \\
\hline $\mathrm{EU}$ & 1.0343 & 1.0061 & 0.9953 & 1.0320 & 1.0026 & $0.9811 * *$ & $0.9599 * * *$ & $0.9586^{* * * *}$ & $0.9594 * * *$ & $0.9065^{* * *}$ & $0.9487 * * *$ \\
\hline India & $0.9496 * *$ & $0.8743^{* * *}$ & $0.9078 * * *$ & $0.9319 * * *$ & $0.9775^{*}$ & 1.0067 & 1.0975 & 1.1393 & 1.3813 & 1.1206 & 1.4460 \\
\hline Japan & $0.9330 * * *$ & $0.9602 * * *$ & 1.0386 & 0.9946 & 1.0083 & 1.0040 & 1.0149 & $0.9926^{*}$ & 1.0248 & $0.9155^{* * *}$ & $0.8974 * * *$ \\
\hline Korea & $0.9779 * *$ & $0.9632 * * *$ & $0.9783^{* *}$ & $0.9784 * *$ & $0.9847 *$ & 1.0081 & 1.0281 & 1.0595 & 1.1184 & 1.0180 & $0.7614 * * *$ \\
\hline
\end{tabular}




\begin{tabular}{|c|c|c|c|c|c|c|c|c|c|c|c|}
\hline South Africa & $0.7674 * * *$ & $0.8750 * *$ & 0.9765 & 1.1019 & 1.1274 & 1.0424 & 1.0522 & 1.0007 & 1.1684 & 1.1817 & 1.6690 \\
\hline Russia & $0.9872^{*}$ & $0.9894 *$ & $0.9458 * * *$ & $0.9406^{* * *}$ & $0.9295 * * *$ & $0.9482 * * *$ & $0.9515 * * *$ & 0.9938 & 1.3140 & 1.6255 & 1.2187 \\
\hline Singapore & 0.9917 & 0.9913 & 1.0181 & 0.9873 & $0.9436 * *$ & 0.98911 & 1.1222 & 1.3979 & 1.3585 & 1.4468 & 1.9503 \\
\hline UK & $0.9834^{*}$ & $0.9646^{* *}$ & $0.9795^{* *}$ & $0.9815^{*}$ & $0.9823 *$ & $0.9713 * *$ & 1.0074 & 1.0540 & 1.1011 & 1.3924 & 1.5642 \\
\hline
\end{tabular}

Notes: All figures are relative RMSFE (R-RMSFE), i.e., ratios of MSFEs to the MSFE of the historical average benchmark model. A R-RMSFE below unity indicates that the forecasting model over-performs the benchmark forecasting model according to the MSFE metric. *,**,** denote rejection of the null of equal MSEs according to the McCracken (2007) MSE-F statistic at 10\%,5\%, and 1\% level of significance, respectively. h-step-ahead forecasts are generated recursively. 